
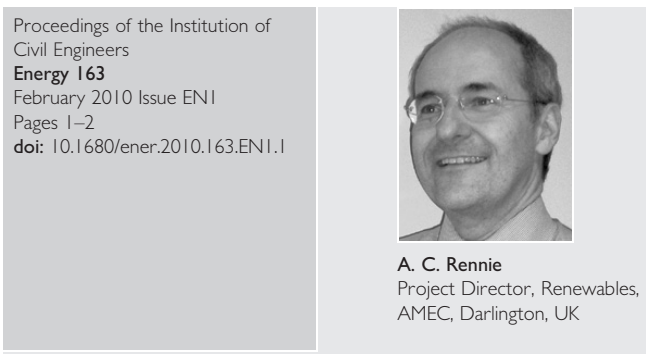

\title{
Editorial: Climate change, embedded energy and uncertainty
}

A. C. Rennie MBA, BE, MIEAust, CPEng

Conversion of resources for human energy needs is the major contributor to climate change. Those conversions help create goods and services and, in so doing, embed the emissions from resource conversion, such as released $\mathrm{CO}_{2}$, in what we consume. The papers in this issue are further examples of the technology needed to change from the 'business as usual' of energy conversion, but are dependent on political will and the legal value placed on avoiding anthropogenic emissions.

Recently, global climate change consensus has been set in the context of the Conference of the Parties at Copenhagen (United Nations Climate Change Conference, COP15) in December 2009, the outcomes of which were expected to help clarify national and business decision making.

\section{COPI5 - PROGRESS AND LOST OPPORTUNITY}

The positive outcomes include recognising anthropogenic interference with the climate system, a noted aim to limit global temperature rises to less than $2{ }^{\circ} \mathrm{C}$, some intended action on deforestation and funding aimed to assist adaptation actions in developing countries.

The opportunities lost are time and clarity of signals to business, and binding political agreements and targets. The outcomes in setting better collective targets and working beyond the current Kyoto Protocol were very poor compared to the expectations over the previous two years. The entire process of work before and during COP15 was so bad that it seems that future progress will have to be done by other groupings of nations, as the 192 delegations demonstrated they could not agree on a collective framework for action. It is not possible for outside observers to be sure of individual motivations of delegates, but there did seem to be a stream of trivial and myopic positions that made substantive progress impossible. For industrial sectors looking for leadership, the COP15 process has deferred clarity on our collective actions for about two years on issues such as 'a price' for $\mathrm{CO}_{2}$.

\section{NATIONAL OPPORTUNITIES}

The COP15 outcomes do throw attention to national goals. Indeed, there is a lot for the industrial sectors to consider in mitigation actions at this level, as a quarter of the attendee countries are responsible for 80 percent of global warming emissions. For nations, it is not just about pricing $\mathrm{CO}_{2}$, in say the European emissions trading scheme. The changes from business as usual are justified by related and other factors, and require technology and sector-specific action. Additional drivers for change include security of energy supplies, diversity of energy supplies, reduced energy imports, industrial development, local health and local environmental impacts.

Examples of focused high incentives to reduce green-house gases are feed-in tariffs and obligations on energy suppliers. These vary in their detailed scope but can imply $\mathrm{CO}_{2}$ values twice to over 10 times traded $\mathrm{CO}_{2}$ credits. These can and should drive investment decisions, but require careful consideration of the financial risks.

There are two problems for an industrial sector with local incentives or constraints on emissions, besides those of the limits and administration of incentives.

Firstly, will the driver still be in place after the time taken to design, gain consent and become eligible for the incentive has passed? One plant may take three to seven years to bring to operation and a whole fleet or group of assets may take over 20 years to replace, so whole-hearted commitment to such investment is risky.

Also, there is the problem of embedded $\mathrm{CO}_{2}$ in goods and services through the emissions needed to create them. Competition from imports with embedded $\mathrm{CO}_{2}$, or being disadvantaged in exporting goods and services with higher cost mitigation of embedded $\mathrm{CO}_{2}$, is an immediate issue and may lead to relocation of activity to other countries. Different sectors have different abilities to change and, in many cases, regulation to require lower green-house gas use is the simple solution, but good regulation across national boundaries is difficult. The use of a carbon tax approach to direct and embedded $\mathrm{CO}_{2}$ may also be useful at a national government level.

\section{ADVANCING TECHNICAL KNOWLEDGE}

The value of developing national aims is illustrated in the work of institutes and how they can share knowledge across boundaries, as discussed in the paper on coal gasification and IGCCs by K. Scott Weil, chief scientist at the Pacific Northwest National Laboratory in the USA (Weil, 2010). This paper illustrates very well the reasons why gasifiers are not the dominant power conversion for coal now. With recognition of the value in reduced $\mathrm{CO}_{2}$ emissions, however, there is a good engineering case for IGCCs with carbon capture and storage (CCS). The average cost advantages reported in the paper are 
also reviewed elsewhere (Al-Juaied and Whitmore, 2009). The problem is that if you do not know four to five years before the plant is operational whether or not CCS will be required by regulation or market value of $\mathrm{CO}_{2}$, then the design decision is likely to be a conventional, supercritical design with an option for post combustion capture to be deferred as long as possible. The lower power prices and environmental benefits of an IGCC with CCS design decision require long-term national government commitments on CCS and, for many governments, this is now likely to be blurred for two years by the prevarication at COP15.

An example of where a country should lead development work is the UK with its marine energy resource. This is large scale and relatively convenient for a large grid infrastructure. Wavehub is a concept designed to provide infrastructure for a number of wave-energy conversion technologies off the coast of Cornwall. The approach to considering the environmental impact is shown in the paper by Li and Phillips (2010). This involves a public agency, the SWRDA, enabling common infrastructure for early commercial deployment, which is a difficult development phase for start-up companies to fund. On the tidal energy side, the UK has many exciting technologies under investigation, such as the Triton approach addressing deployment and maintenance issues in the paper by Armstrong (2010) from TidalStream Ltd., a private company at least encouraged by government policies and funding that are favourable to the potential of marine energy. In both cases, due to open commercial environment and government policies, the results from the UK will directly and indirectly be available to be used wherever the natural circumstances of marine energy and energy use coincide.

Lee (2010) addresses the state and issues of CHP in the UK, including issues for countries with mild winters and existing infrastructure reliant on natural gas, but goes further in two useful ways. The paper is helpful in describing the added value of torrefaction for biomass. Most importantly, it puts CHP in the context of the necessary $\mathrm{CO}_{2}$ emissions reduction from natural gas in future decades and, where biomass is a limited resource to be used wisely, an issue that is not just for the UK.

\section{EMBEDDED ENERGY AND CLIMATE CHANGE}

Repeating a theme from David Hirst's editorial in this journal (Hirst, 2007), engineers who can quantify and prioritise risks in managing climate change are important in enabling informed choices, because resolving when, where and how energy is sourced, efficiently embedded in things we need and the impacts on the environment, affects us all.

At a global level, we have been let down by many individual actions of a number of delegations at COP15, making the assessments of engineers more difficult, as there are fewer global mechanisms and agreements to underpin national actions. Positively though, there are opportunities in the enlightened self interest of some nations. Politicians and negotiators at national and global levels need to appreciate the long timescales for action in the industrial sectors, and the need for policy certainty over even longer periods to effect mitigation of climate change and need to progress agreements in the very short term.

Engineers should continue to do what they are good at, doing the art of the possible in these uncertain circumstances. We have learnt the value of acting safely. Likewise, in the case of climate change, whatever the immediate pressures, engineers should see and state the case for promoting decisions that mitigate and adapt to climate change.

\section{REFERENCES}

Al-Juaied MA and Whitmore A (2009) Realistic Costs of Carbon Capture. Discussion Paper 2009-08, Energy Technology Innovation Research Group. Belfer Center for Science and International Affairs, Cambridge, Mass.

Armstrong J (2010) Briefing: 10 MW Triton - a breakthrough in tidal stream power. Proceedings of the Institution of Civil Engineers, Energy 163(1): 3-5.

Hirst DM (2007) Editorial: Reducing $\mathrm{CO}_{2}$ emissions and maintaining economic growth. Proceedings of the Institution of Civil Engineers, Energy 160(4): 135-136.

Lee R (2010) Combined heat and power in a carbon-constrained world. Proceedings of the Institution of Civil Engineers, Energy 163(1): 31-39.

Li B and Phillips M (2010) South West wave energy hub: coastal impact and wave energy. Proceedings of the Institution of Civil Engineers, Energy 163(1): 17-29.

Weil KS (2010) Coal gasification and IGCC technology: a brief primer. Proceedings of the Institution of Civil Engineers, Energy 163(1): 7-16. 